\title{
XAFS Characterization of Li Deintercalation in Rechargeable Lithium Battery Materials, $\mathrm{LiCoO}_{2}-\mathrm{LiNiO}_{2}$
}

\author{
I. Nakai, K. Takahashi, Y. Shiraishi and T. Nakagome \\ Department of Applied Chemistry, Faculty of Science, Science University of Tokyo, Kagurazaka, \\ Shinjuku, Tokyo 162, Japan
}

\begin{abstract}
I n$ situ measurements of the $\mathrm{Ni}$ and $\mathrm{Co} \mathrm{K}$-edge $\mathrm{XAFS}$ spectra of $\mathrm{Li}_{1-\mathrm{x}} \mathrm{NiO}_{2}$ and $\mathrm{Li}_{1-x} \mathrm{CoO}_{2}$ as a function of $x$ were successfully carried out for the first time using an electrochemical cell. It is observed that a local Iahn-Teller distortion of the $\mathrm{NiO}_{6}$ octahedron in $\mathrm{LiNiO}_{2}$ was reduced with deintercalation of $\mathrm{Li}$ which caused oxidation of the Jahn-Teller $\mathrm{d}^{7} \mathrm{Ni}^{3+}$ ion to $\mathrm{d}^{\mathrm{i}} \mathrm{Ni}^{4+}$ ion. A substitution of $\mathrm{Co}$ for $\mathrm{Ni}$ in $\mathrm{LiNiO}_{2}$ also reduced the local distortion of the $\mathrm{NiO}_{6}$ octahedron. XANES spectra of $\mathrm{LiNiO}_{2}$ shifted to higher energy side with increasing $\mathrm{x}$ while an abrupt shape change was observed in the XANES spectra of $\mathrm{Li}_{\mathrm{l}-\mathrm{x}} \mathrm{COO}_{2}$ corresponding to phase transition.
\end{abstract}

\section{Introduction}

$\mathrm{LiNiO}_{2}$ is one of the promising candidates for next electrode material for rechargeable lithium battery subsequent to $\mathrm{LiCoO}_{2}[1]$. However, a rather complicated phase transition appeared in $\mathrm{Li}_{1 \times \mathrm{x}} \mathrm{NiO}_{2}$ during the electrochemical deintercalation and intercalation process[2], which requires detailed structural characterization of these phases by XAFS technique. This paper reports results of the first in situ measurements of the $\mathrm{XAFS}_{\mathrm{Spectra}}$ of $\mathrm{LiNiO}_{2}$ and $\mathrm{LiCoO}_{2}$ during electrochemical deintercalation. Rougier et a1. [3] reported XAFS analysis of $\mathrm{LiNiO}_{2}$ and found a local distortion of the $\mathrm{NiO}_{6}$ octahedron due to the Jahn-Teller effect of the $\mathrm{Ni}^{3+}$ ion in the low spin state.

\section{Experimental}

Samples used were $\mathrm{Li}_{1-\mathrm{x}} \mathrm{NiO}_{2}$ and $\mathrm{Li}_{1-\mathrm{x}} \mathrm{CoO}_{2}$ with various $\mathrm{x}$ values and $\mathrm{Li}(\mathrm{Ni}, \mathrm{Co}) \mathrm{O}_{2}$. They were prepared by sintering method. The electrochemical deintercalation of $\mathrm{Li}$ was carried out by using a lithium cell. Ni and Co $\mathrm{K}$-edge XAFS data were measured in transmission mode at BL-7C, Photon Factory, KEK, Japan using Si(111) double-crystal monochromator. Low temperature experiments were also carried out using a tape sample and CTI Model 22C CRYODYNE cryocooler at temperatures of 200,110 and 20K. In situ measurements were made at room temperature using a XAFS cell for electrochemical deintercalation and intercalation newly developed for this experiment. Li ion was electrochemically deintercalated from the cathode material at a certain voltage and the XAFS data were measured without taking out the sample from the cell. $\mathrm{LiNiO}_{2}$ and $\mathrm{LiCoO}_{2}$ were used as the cathode and Li metal was used as the anode with suitable thickness for the transmission XAFS experiment.

\section{Results and Discussion}

Figures 1 shows the $\mathrm{Ni} \mathrm{K}$-edge XANES spectra of $\mathrm{LiNiO}_{2}$ measured at $20,110,200$ and $290 \mathrm{~K}$. Fourier transforms (FT) of $\mathbf{k}^{3}$ weighted $\mathrm{Ni}$ and $\mathrm{Co} \mathrm{K}$-edge EXAFS are given in Fig. 2 . Figure 1 shows that the spectra measured at different temperature are all equal to each other and the electronic structure of $\mathrm{Ni}$ were not significantly affected by their temperature. The first peak at around $1.5 \AA$ in Fig. 2 corresponds to metal-oxygen interaction in the first coordination sphere, the second one at $2.4 \AA$ is metal-metal interaction in the second coordination sphere. Simulated data calculated with the FEFF6 code [4] disclosed that the peaks at 4.6 and $5.4 \AA$ are contribution mainly from metal-metal interactions and the focusing effect due to the multiple scattering is found in the latter peak. A comparison of the Ni-O peak in FT with that of the Co-O peak indicates that the former peak is abnormally lower than that of the latter. The low temperature experiments showed that the peak height did not increase even at $20 \mathrm{~K}$ precluding an effect of thermal vibration as a reason for the low peak height.

Figure 3 indicates XANES spectra measured using the in situ cell. As the $\mathrm{Li}$ ion is electrochemically deintercalated, the $\mathrm{Ni} \mathrm{K}$-edge of $\mathrm{LiNiO}_{2}$ shifts to higher energy side indicating an increase in the positive charge of the $\mathrm{Ni}$

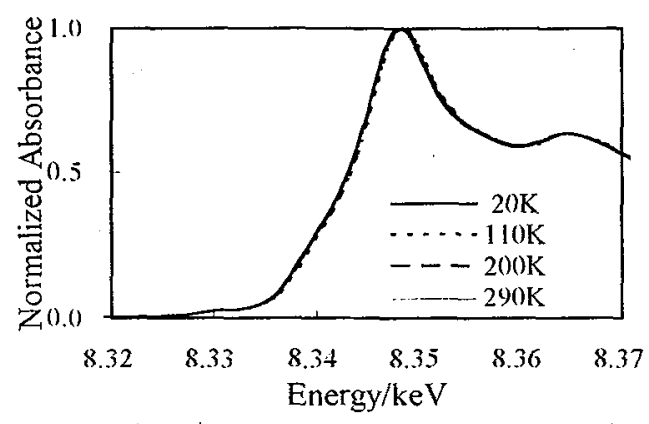

Figure 1: Ni K-XANES spectra at various temperatures 

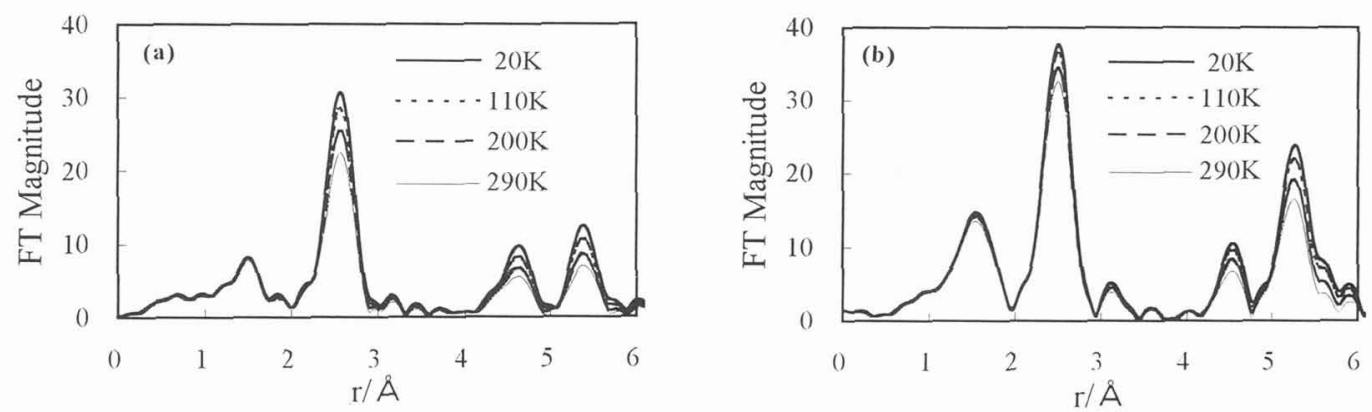

Figure 2: Fourier transforms of the $\mathrm{k}^{3} \chi(\mathrm{k})$ of (a) $\mathrm{LiNiO}_{2}, \mathrm{Ni} \mathrm{K}$-edge (b) $\mathrm{LiCoO}_{2}$, Co K-edge
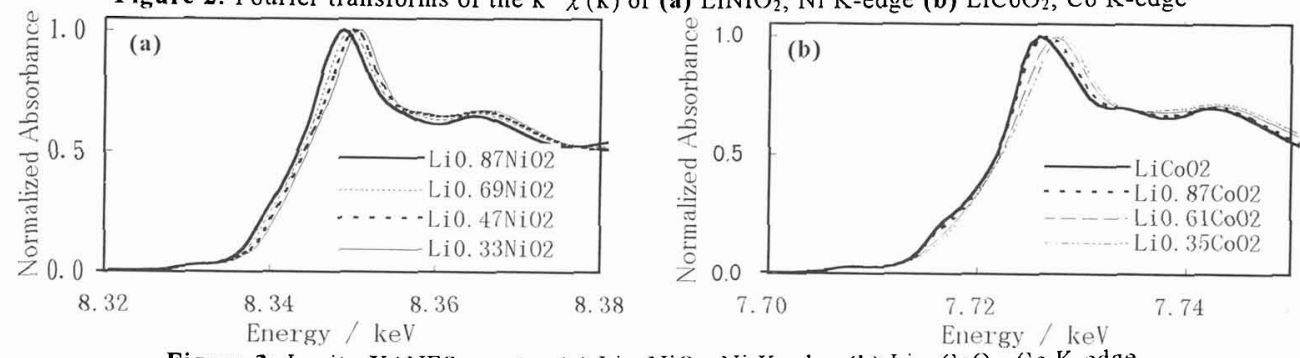

Figure 3: In situ XANES spectra (a) $\mathrm{Li}_{1-x} \mathrm{NiO}_{2}$, Ni K-edge (b) $\mathrm{Li}_{1-x} \mathrm{CoO}_{2}$, Co K-edge
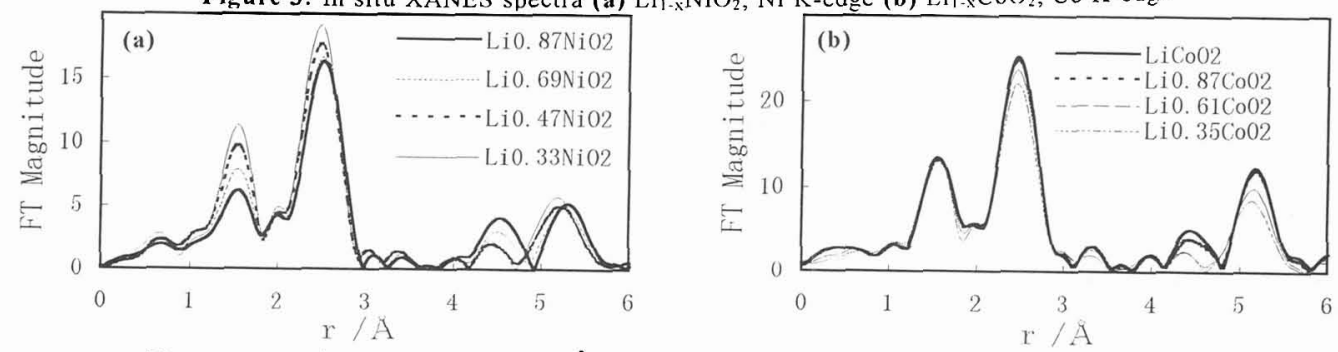

Figure 4: Fourier transforms of the $\mathrm{k}^{3} \chi(\mathrm{k})$ of (a) $\mathrm{Li}_{1 \cdot \times} \mathrm{NiO}_{2}$, $\mathrm{Ni} \mathrm{K}$-edge (b) $\mathrm{Li}_{1 \cdot \times} \mathrm{CoO}_{2}$, Co K-edge

ion. On the other hand, the spectra of $\mathrm{LiCoO}_{2}$ showed an abrupt change in the edge shape at $x=0.39$ indicating change of the local structure, which corresponds to trigonal to monoclinic transition known for $\mathrm{Li}_{1-x} \mathrm{CoO}_{2}$ at $x=c$.a. $0.5[5]$. FT of $\mathrm{Ni}$ and $\mathrm{Co} \mathrm{K}$-edge EXAFS measured using the in situ cell are given in Fig. 4 (a) and (b), respectively. It is remarkable that the $\mathrm{Ni}-\mathrm{O}$ peak height increases with deintercalation of $\mathrm{Li}$, while the $\mathrm{Co}-\mathrm{O}$ peak height remains almost constant. Rougier et al [3] reported that there is a local Jahn-Teller distortion in $\mathrm{LiNiO}_{2}$. Crystallographically, the $\mathrm{Ni}$ atom is located at the $3 \mathrm{~b}$ site of $\mathrm{R} \overline{3} \mathrm{~m}$ lattice with octahedral coordination with 60 atoms at an equal distance. Therefore, a distortion from the octahedron could not occur in long range but it should be a local effect. The abnormally low peak height could be ascribed to the Jahn-Teller distortion from the true octahedral coordination yielding such as four short and two long Ni-O distances. This results in much lower peak in the FT than that of regular octahedral Ni-O distance due to the interaction of the imaginary and real parts of FT. Low spin $\mathrm{Ni}^{3+}$ is $\mathrm{d}^{7} \mathrm{Jahn}-\mathrm{Teller}$ ion which has an electronic configuration of $t_{2 g}{ }^{6} \mathrm{e}_{\mathrm{g}}{ }^{7}$. Deintercalation of $\mathrm{Li}$ cause oxidation of $\mathrm{Ni}^{3+}$ to $\mathrm{Ni}^{4+}$ resulting in $\mathrm{t}_{2 g}{ }^{6} \mathrm{e}_{\mathrm{g}}{ }^{6}$ state, which does not present a Jahn-Teller distortion. A substitution of $\mathrm{Co}$ for $\mathrm{Ni}$ in $\mathrm{LiNiO}_{2}$ causes increase in the peak heights (Fig. 5). This phenomena also could be explained by the Jahn-Teller effect that the substitution of $\mathrm{Co}^{3+}$, which is $\mathrm{d}^{6}$ ion, may reduce the local distortion of the $\mathrm{Ni}$ ion.

Acknowledgments

The authors are grateful to Mrs. F. Nishikawa and T.Himeda for their kind help in the experiments.

References

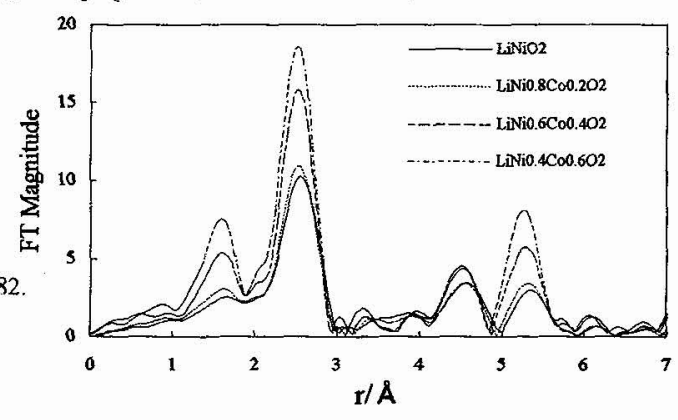

Figure 5: FT of the $\mathrm{k}^{3}$ weighted Ni K-edge EXAFS of $\mathrm{Li}(\mathrm{Ni}, \mathrm{Co}) \mathrm{O}_{2}$

Phys.Rev.B,52(1995)2995-3009.
[5] Reimers J.N., Dahn I. R. J. Electrochem. Soc.,139(1994)2091-2097. 